\title{
EFICIÊNCIA E DISTRIBUIÇÃO DE NITROGÊNIO APLICADO EM COBERTURA NA CULTURA DE MILHO CONSORCIADA COM BRACHIARIA RUZIZIENSIS, CULTIVADA NO SISTEMA SANTA FÉ
}

\author{
WALDO ALEJANDRO RUBÉN LARA-CABEZAS $\left({ }^{2 *}\right)$; RODRIGO VIEIRA DE PÁDUA $\left({ }^{3}\right)$
}

\begin{abstract}
RESUMO
No sistema Integração Lavoura Pecuária (ILP), com opção pelo sistema Santa Fé - milho em consórcio com a Brachiaria ruziziensis, Germain \& Edvard, são viabilizadas a produção de grãos e a forrageira com a finalidade de cobertura de solo e ou pastejo na entressafra no sistema plantio direto (SPD). Foi desenvolvido um experimento na Fazenda Canadá, município de Uberlândia, MG, em Latossolo Vermelho distrófico, de textura média (218 $\mathrm{g} \mathrm{kg}^{-1}$ de argila), no sistema Santa Fé objetivando-se: a) quantificar a eficiência e distribuição de $\mathrm{N}$-aplicado em cobertura na cultura de milho e de B. ruziziensis; b) quantificar o teor de $\mathrm{S}_{-} \mathrm{SO}_{4}^{2-}$ distribuído no perfil de solo após a aplicação de $\mathrm{N}$ em cobertura e c) produção da massa de matéria seca (MMS) da B. ruziziensis na colheita do milho e aos 55 dias após. Utilizou-se o delineamento inteiramente casualizado, com oito tratamentos dispostos em faixas, com $100 \mathrm{~m}$ de comprimento e $4,5 \mathrm{~m}$ de largura, com quatro repetições. Os tratamentos foram: milho solteiro e consorciado sem $\mathrm{N}$ em cobertura, milho solteiro e consorciado com mistura de uréia e sulfato de amônio, relação 1:1 em nutriente, milho solteiro e consorciado com uréia em cobertura e milho solteiro e consorciado com sulfato de amônio em cobertura. Foram efetuadas duas coberturas de N, utilizando-se fontes marcadas com ${ }^{15} \mathrm{~N}$, em estádios de dois a três folhas e cinco a seis folhas, aplicando-se a lanço, na entrelinha e incorporada no meio das entrelinhas, respectivamente, 40 e $64 \mathrm{~kg} \mathrm{ha}^{-1}$ de N. A B. ruziziensis foi semeada em dose de $12 \mathrm{~kg} \mathrm{ha}^{-1} \mathrm{em}$ uma única fileira, na entrelinha, no estádio de cinco a seis folhas, e simultaneamente à segunda cobertura nitrogenada. Conforme os resultados, aos 23 dias após a segunda cobertura, na camada de 20 até $60 \mathrm{~cm}$, as concentrações decrescentes de $\mathrm{S}_{-} \mathrm{SO}_{4}{ }_{4}^{2-}$ no solo foram para sulfato de amônio > uréia + sulfato de amônio $>$ uréia = testemunha, nos tratamentos de milho solteiro. A eficiência média do N-fertilizante no estádio de duas a três folhas foi de $45,0 \%$ do $\mathrm{N}$-aplicado, independentemente da fonte aplicada. Na segunda cobertura foi, em média de $60,7 \%$, independentemente do manejo e das fontes aplicadas, com destaque para o tratamento com sulfato de amônio ( $73,7 \%$ em média). Em ambas as culturas e, até a colheita de milho, foram assimilados $54,5 \mathrm{~kg} \mathrm{ha}^{-1}$ do N-aplicado em cobertura, sendo $97,1 \%$ e 2,9\% distribuídos na parte aérea no milho e $B$. ruziziensis, respectivamente. Não houve diferença de produtividade, exceto em relação às testemunhas. Na $B$. ruziziensis constatou-se acréscimo médio na MMS de $61,9 \%$ aos 55 dias após a colheita de milho. Pode-se concluir que, com a B. ruziziensis, não foi afetada a eficiência de $\mathrm{N}$-aplicado e que, com sulfato de amônio seguido da mistura uréia + sulfato de amônio, houve mais contribuição para recuperação de N-fertilizante pelo milho. Grande proporção do N-fertilizante assimilado pelas culturas foi recuperada pelo milho.
\end{abstract}

Palavra-chave: consórcio milho e B. ruziziensis, isótopo ${ }^{15} \mathrm{~N}$, cobertura de solo, forragem, entressafra.

$\left({ }^{1}\right)$ Recebido para publicação em 24 de outubro de 2005 e aceito em 6 de novembro de 2006.

(2) Pólo Regional Noroeste Paulista - Votuporanga, DDD/APTA/SAA. Caixa Postal 61, 15500-000 Votuporanga (SP). E-mail: waldolar@aptaregional.sp.gov.br (*autor correspondente)

$\left({ }^{3}\right)$ Bunge Fertilizantes SA, Rua C, nº 19, sala 1, 3. ${ }^{\circ}$ andar, Sudeste Goiânia, GO. E-mail: rodrigo.paiva@bunge.com 


\title{
ABSTRACT \\ EFFICIENCY AND DISTRIBUTION OF NITROGEN APPLIED ON SIDE-DRESSING IN CORN INTERCROPPED WITH BRACHIARIA RUZIZIENSIS, CULTIVATED IN SANTA FE SYSTEM
}

\begin{abstract}
Within the system of Integrated Cattle Farming, corn intercropping with Brachiaria ruziziensis, Germann \& Edvard, the option called Santa Fé system, allow for the production of grains and the production of forrage during the dry season, with the purpose of covering the soil and/or food production for cattle. An experiment was carried out at Fazenda Canadá, Uberlândia, Minas Gerais State, Brazil, in a soil of medium texture (218 $\mathrm{g} \mathrm{kg}^{-1}$ of clay), in Santa Fé system with the objectives of: a) to quantify the efficiency of using the $\mathrm{N}$-applied in side-dressing on corn and B. ruziziensis; b) to quantify the $\mathrm{SO}_{4}{ }^{2-}-\mathrm{S}$ content distributed on soil profile after the application of $\mathrm{N}$ side-dressing and c) dry matter of B. ruziziensis at harvest of corn and 55 days after. An entirely random design was established, with eight treatments with four replications. The treatments were: single corn crop and intercropped with B. ruziziensis without $\mathrm{N}$-applied (controls), single corn crop and intercropped one with urea mixture and ammonium sulphate, at a ratio of 1:1 in nutrient, single corn crop and intercropped with urea and single corn crop and intercropped with ammonium sulphate. Two N-sidedress applications were made, using sources labelled with ${ }^{15} \mathrm{~N}$, in stages from two to three leaves and five to six leaves, applied between rows and incorporated between rows, respectively, using 40 and $64 \mathrm{~kg} \mathrm{ha}^{-1}$ of $\mathrm{N}$. The B. ruziziensis was sown at a quantity of 12 $\mathrm{kg} \mathrm{ha}^{-1}$ in a single line in the middle of the corn rows, at the stage of five to six leaves. Twenty three days after the second $\mathrm{N}$-sidedressing, the decreasing concentrations of $\mathrm{SO}_{4}^{2-}-\mathrm{S}$ in the 20 to $60 \mathrm{~cm}$ layer of soil profile went to ammonium sulphate $>$ urea + ammonium sulphate $>$ urea $=$ controls, at the treatments of single corn crop. The average efficiency of $\mathrm{N}$-fertilizer at two to three leaves stage was $45.0 \%$ of the $\mathrm{N}$-applied. The average efficiency of $\mathrm{N}$-applied at second stage was $60.7 \%$, the treatment with ammonium sulphate distinguishing itself $(73.7 \%$ on average). Up to corn harvest, both cultures assimilated $54.5 \mathrm{~kg}$ $\mathrm{ha}^{-1}$ of the N-applied, 97.1 and $2.9 \%$ being distributed to the aerial parts of the corn and B. ruziziensis, respectively. There was no grain productivity difference, except in relation to the controls. The $B$. ruziziensis showed an increasing average of $61.9 \%$ dry matter, 55 days after corn harvest. For the purpose of this study, it can be concluded that B. ruziziensis did not affect the efficiency of the $\mathrm{N}$-applied and that ammonium sulphate followed by the mixture of urea + ammonium sulphate contributed to a greater recovery of $\mathrm{N}$-fertilizer by corn plant. High proportion of $\mathrm{N}$-fertilizer assimilated for both cultures was recovery by corn.
\end{abstract}

Key words: intercropping corn - B. ruziziensis, ${ }^{15} \mathrm{~N}$ isotope, cover crops, forage, out-of season.

\section{INTRODUÇÃO}

O sistema Santa Fé, opção Integração Lavoura Pecuária (ILP) no Sistema Plantio Direto (SPD), foi desenvolvido na Fazenda Santa Fé, em Santa Helena de Goiás, GO, com o objetivo de produzir forragem para a entressafra e palhada para o SPD (KLUTHCOUSKi e AidAR, 2003). No país estimase que a área degradada de pastagens esteja na ordem de 60.000 .000 ha (Oliveira, 2001) e que, com a recuperação mediante esse sistema venha a ser acrescida a qualidade dos atributos físicos, químicos e biológicos de solo. SALton et al. (1995) salientam também que com a ILP há aumento da lotação animal, otimização de maquinário e obtenção de duas safras no ano: grãos e carne/leite. O sistema fundamenta-se na produção consorciada de grãos milho, soja, milheto, sorgo ou arroz, com forrageiras, principalmente as do gênero Brachiaria spp., visando à produção forrageira para a entressafra e palha de cobertura para o SPD (KLUTHCOUSKI e AidAR, 2003; KLuthcouski et al., 2004).
Neste contexto, no fim da década de 80 , o agropecuarista Ake van der Vinne fez as primeiras tentativas em ILP, mostrando que a propriedade rural deve ser uma "indústria" de proteína vegetal e animal (BORGES, 2004). Valores médios de 6.561 e $6.553 \mathrm{~kg} \mathrm{ha}^{-1}$ de milho foram obtidos tanto em cultivo exclusivo como no consorciado, respectivamente, em diversos experimentos realizados nas safras de 1998 até 2001, em Goiás, Mato Grosso e Bahia (KluthCouski e AidAR, 2003).

AGNEs et al. (2004), em Viçosa (MG), observaram que a produtividade de grãos de milho não foi afetada por diferentes modalidades de semeadura da $B$. brizantha: a lanço; na entrelinha e na linha do milho, evidenciando-se a pouca competitividade exercida pela braquiária. De fato, PorTes et al. (2000), estudando a $B$. decumbens, em Goiânia, GO, verificaram insuficiente suprimento de fotoassimilados à braquiária devido ao sombreamento exercido pelo cereal.

MAteus et al. (2004) avaliaram a produção de milho forrageiro em dois espaçamentos: 0,45 e 0,90 m, em consórcio com $B$. brizantha na linha, na entrelinha 
e, no milho solteiro, e demonstraram aumento significativo na produção do milho com o menor espaçamento e maior produção de MMS da silagem em consórcio com a braquiária; com o consórcio não foi comprometida a proporção de grãos na forragem de milho.

Ainda não existem suficientes trabalhos publicados sobre a dinâmica de N no sistema Santa Fé. CAPOBIANCO et al (2004) não obtiveram resposta positiva do milho às doses de nitrogênio $(\mathrm{N})$, em cultivo exclusivo ou consorciado com B. brizantha na linha de semeadura. CAMPOS (2004) avaliou o efeito do $\mathrm{N}$-sulfato de amônio em pré-semeadura ou em cobertura na cultura do milho consorciada com Brachiaria, em Latossolo Vermelho distrófico típico, muito argiloso, no Distrito Federal; quantificou no milho uma eficiência de recuperação de $79 \%$ e $48 \%$ do $\mathrm{N}$ aplicado, respectivamente, embora não houvesse diferença significativa na produtividade entre os tratamentos.

Quanto à distribuição quantitativa do $\mathrm{N}$ aplicado em cobertura nas culturas do milho e da braquiária não há registros na literatura.

Os objetivos deste trabalho, portanto, foram os de quantificar a eficiência e a distribuição do $\mathrm{N}$ aplicado em cobertura, proveniente de diferentes fontes nitrogenadas, em cultivo exclusivo e consorciado com B. ruziziensis (sistema Santa Fé), e os seus efeitos na produtividade de grãos; na distribuição de $\mathrm{S}_{-} \mathrm{SO}_{4}^{2-}$ no perfil de solo após a aplicação de $\mathrm{N}$ e na produção de MMS da braquiária por ocasião da colheita do milho e aos 55 dias após a colheita.

\section{MATERIAL E MÉTODOS}

O experimento foi instalado na Fazenda Canadá, do Grupo Algar, no município de Uberlândia (MG), em Latossolo Vermelho Distrófico (EMBRAPA, 1999), contendo $218 \mathrm{~g} \mathrm{~kg}^{-1}$ de argila no perfil de $0 \mathrm{a}$ $20 \mathrm{~cm}$ de profundidade, com as seguintes características químicas: $\mathrm{pH}$ (água) 5,1; P (Mehlich-1) $16,5 \mathrm{mg} \mathrm{dm}^{-3} ; \mathrm{K}+\left(\right.$ Mehlich-1) 0,92 mmol $_{\mathrm{c}} \mathrm{dm}^{-3}$, CTC $41,9 \mathrm{mmol}_{\mathrm{c}} \mathrm{dm}^{-3}$, saturação por bases $26,1 \%$; saturação por $\mathrm{Al}^{3+} 9,2 \%$ e matéria orgânica $16,0 \mathrm{~g}$ $\mathrm{dm}^{-3}$. O solo foi amostrado em oito pontos na linha de soja, na safra 2002/2003 e em 40 pontos na entrelinha, segundo procedimento indicado por Anghinoni e SAlEt (1998), para o SPD. No outonoinverno de 2003, a área experimental foi deixada em pousio.

A distribuição da precipitação pluvial mensal durante o ciclo da cultura do milho e, até aos 55 dias após a colheita, em maio de 2004, é mostrada na Figura 1. Em 21/10/2003 foi efetuado o dessecamento na área experimental, com $3 \mathrm{~L} \mathrm{ha}^{-1}$ de glifosate e aos sete dias após, foi semeado o milho híbrido DKB 390, na densidade de 63.300 sementes ha ${ }^{-1}$ e no espaçamento de $0,75 \mathrm{~m}$. Para todos os tratamentos realizou-se, no sulco de semeadura, a aplicação de $357 \mathrm{~kg} \mathrm{ha}^{-1} \mathrm{do}$ formulado 10-28-14 e de sais de $\operatorname{Zn~}(0,25 \%$ de $\mathrm{Zn})$ e de B como ulexita $(0,32 \%$ de B), em doses de 0,89 e $1,14 \mathrm{~kg} \mathrm{ha}^{-1}$ respectivamente.

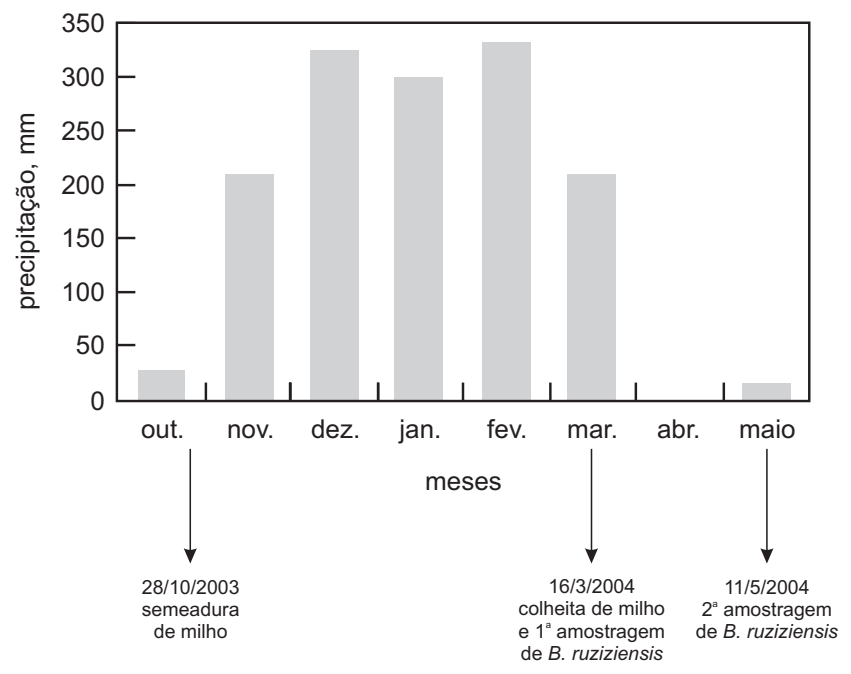

Figura 1. Distribuição da precipitação pluvial mensal durante o ciclo das culturas de milho e Brachiaria ruziziensis ava1iada na fazenda Canadá Uberlândia, MG.

A adubação nitrogenada em cobertura de $104 \mathrm{~kg} \mathrm{ha}^{-1}$, foi parcelada em duas vezes no estádio de duas a três folhas e cinco a seis folhas, respectivamente, sendo a primeira aplicada a lanço, nas entrelinhas, na dose de $40 \mathrm{~kg} \mathrm{ha}^{-1} \mathrm{de}$ $\mathrm{N}$ e a segunda, incorporada no meio da entrelinha, na dose de $64 \mathrm{~kg} \mathrm{ha}^{-1}$ de $\mathrm{N}$, com maquinário apropriado. Os oito tratamentos de cobertura nitrogenada foram implantados em delineamento inteiramente casualizado, em esquema de faixas, com quatro repetições: zero de $\mathrm{N}$ no milho solteiro e consorciado com Brachiaria ruziziensis; e as fontes de $\mathrm{N}$ nas formas de uréia; sulfato de amônio e a mistura uréia + sulfato de amônio com relação $1: 1$ de $\mathrm{N}$, aplicadas na presença ou ausência de B. ruziziensis. As parcelas foram constituídas de seis linhas de milho espaçadas de $0,75 \mathrm{~m}$, com $50 \mathrm{~m}$ de comprimento. Como área útil em cada parcela foram consideradas as quatro linhas centrais, desprezando-se $10 \mathrm{~m}$ em cada extremidade. 
Em três das quatro repetições de cada tratamento com cobertura de $\mathrm{N}$, nas duas épocas, foi instalada uma microparcela de $1,5 \mathrm{~m}$ de comprimento e $1,5 \mathrm{~m}$ de largura, incluindo-se duas linhas de plantas, substituindo-se o adubo comercial por adubo marcado com ${ }^{15} \mathrm{~N}$. Este foi aplicado manualmente, simulando-se a operação mecanizada: $\mathrm{CO}-\left({ }^{15} \mathrm{NH}_{2}\right)_{2} \mathrm{com}$ $1,625 \%$ de átomos de ${ }^{15} \mathrm{~N}$ em abundância; $\left({ }^{15} \mathrm{NH}_{4}\right){ }_{2} \mathrm{SO}_{4}$ com $2,074 \%$ de átomos de ${ }^{15} \mathrm{~N}$ em abundância e como mistura de ambas as fontes (1:1 de N) em tratamentos espelhos com $0,998 \%$ e $0,996 \%$ de átomos de ${ }^{15} \mathrm{~N}$ em abundância na uréia misturada com sulfato de amônio não marcado na primeira e segunda coberturas, respectivamente, e 1,222\% e 1,224\% de átomos de ${ }^{15} \mathrm{~N}$ em abundância no sulfato de amônio, com uréia não marcada, na primeira e segunda coberturas respectivamente. $\mathrm{O} \mathrm{N}$-recuperado nas plantas de milho e de Brachiaria, proveniente do fertilizante $\left(\mathrm{N}_{p p f}\right)$, foi calculado segundo as expressões utilizadas no método de diluição isotópica:

$\mathrm{N}_{p p f}(\%)=[(\mathrm{A}-\mathrm{C}) /(\mathrm{B}-\mathrm{C}) \times 100] \times 2$

$\mathrm{N}_{p p f}\left(\mathrm{~kg} \mathrm{ha}^{-1}\right)=\left(\mathrm{N}_{p p f}(\%) / 100\right) \times \mathrm{N}_{\text {tota }} \mathrm{l}\left(\mathrm{kg} \mathrm{ha}^{-1}\right)$

em que:

$\mathrm{A}=$ concentração de ${ }^{15} \mathrm{~N}$ (\% em abundância de átomos de ${ }^{15} \mathrm{~N}$ ) do grão e parte aérea, $\mathrm{B}=$ concentração de ${ }^{15} \mathrm{~N}$ do fertilizante e $\mathrm{C}=$ concentração isotópica natural do solo $\left(0,370 \%\right.$ de átomos em $\left.{ }^{15} \mathrm{~N}\right)$, respectivamente, e $\mathrm{N}_{\text {total }}=$ quantidade de $\mathrm{N}$-total nas diferentes partes da planta, em $\mathrm{kg} \mathrm{ha}^{-1}$.

A eficiência (E) do N-fertilizante (\%) foi determinada pela expressão:

$\mathrm{E}(\%)=\left[\mathrm{N}_{p p f}\left(\mathrm{~kg} \mathrm{ha}^{-1}\right) / \mathrm{Nfa}\left(\mathrm{kg} \mathrm{ha}^{-1}\right)\right] \times 100$

em que:

$\mathrm{N}_{f a}$ é correspondente ao $\mathrm{N}$-fertilizante aplicado.

As sementes de $B$. ruziziensis foram tratadas com ácido sulfúrico concentrado p.a. durante 15 minutos para superação da dormência e aumento do valor de cultivo (V.C.), para um total de $85 \%$ na semeadura. Posteriormente, foram semeadas no estádio de 5-6 folhas do milho, misturadas ao adubo de cobertura, em uma única fileira, no meio da entrelinha do milho, na quantidade de $12 \mathrm{~kg} \mathrm{ha}^{-1}$ de semente, nos tratamentos correspondentes. Por ocasião da colheita do milho, foram retiradas plantas de milho e da braquiária no interior do metro linear central das duas linhas das microparcelas. A planta do milho foi fracionada em: parte aérea (palha + colmo + palha de espiga + sabugo) e grãos. A MMS desse material foi determinada após secagem em estufa com ar forçado a $60^{\circ} \mathrm{C}$, até massa constante. $\mathrm{O} N$ na parte aérea e nos grãos do milho e na parte aérea da braquiária foi determinado por via seca Dumas (RAmos et al., 2001), com posterior determinação da concentração de ${ }^{15} \mathrm{~N}$ por espectrometria de massas, na Embrapa Agrobiologia, Seropédica, RJ.

Em 6/12/2003 e 23/12/2003, aos sete e 23 dias após a segunda cobertura, foram efetuadas amostragens de solo em triplicata, no meio da entrelinha da cultura, nas camadas de 0 a $10 \mathrm{~cm}, 10$ a $20 \mathrm{~cm}, 20$ a 40 e 40 a $60 \mathrm{~cm}$ de profundidade, somente nos tratamentos com uréia, sulfato de amônio e mistura uréia + sulfato de amônio em milho solteiro, para determinação de $\mathrm{S}$-sulfato pelo método de turbidimetria com $\mathrm{BaCl}_{2} \times 2 \mathrm{H}_{2} \mathrm{O}$ (CANTARELla e PROCHNOW, 2001).

No florescimento do milho, em 13/1/2004, foi efetuada a amostragem foliar, coletando-se a folha inferior oposta à espiga, para determinação de $\mathrm{N}$ e $\mathrm{S}$ (Malavolta et al., 1997). Cada amostra consistiu de 10 folhas em três das quatro repetições por tratamento. Nessas plantas foram medidas, também, a altura entre a superfície do solo e a inserção da folha bandeira e o diâmetro do entrenó inferior à inserção da espiga. $\mathrm{Na}$ parcela útil, em duas linhas centrais de $15 \mathrm{~m}$ de comprimento, foi efetuada a colheita de grãos, com 20 a $21 \mathrm{~g} \mathrm{kg-1}$ de umidade, corrigida para $13 \mathrm{~g} \mathrm{~kg}^{-1}$ para a aferição da produtividade.

A produção da MMS da parte aérea da braquiária foi determinada na colheita do milho e aos 55 dias após, nos tratamentos correspondentes, em amostragem de $1 \mathrm{~m}^{2}$, sendo ceifado o material a 15 $\mathrm{cm}$ de altura e colocado para secar em estufa com ar forçado a $60^{\circ} \mathrm{C}$, até massa constante.

Os dados obtidos para cada variável avaliada foram submetidos à análise de variância pelo teste de $\mathrm{F}$ e, para o caso de diferenças significativas, aplicouse o teste de Tukey a $5 \%$.

\section{RESULTADOS E DISCUSSÃO}

A disponibilidade hídrica foi favorável para o crescimento e desenvolvimento da planta de milho (Figura 1). Entre os meses de dezembro de 2003 até fevereiro de 2004 foram registrados aproximadamente $300 \mathrm{~mm}$ de chuva por mês, quantidade suficiente para os requerimentos da cultura que são de 350 a 500 mm no verão, sem necessidade de irrigação (FANCELLI e Dourado Neto, 2000).

Nas figuras $2 a$ e $2 b$, nota-se a distribuição em profundidade, até $60 \mathrm{~cm}$, do S-SO ${ }_{4}^{2-}$, nos tratamentos de milho solteiro, após sete e 23 dias da aplicação da segunda adubação nitrogenada em cobertura respectivamente. Nas camadas superficiais, 0 a $20 \mathrm{~cm}$, 
para as duas épocas, não foi observada diferença no teor de $\mathrm{S}_{-} \mathrm{SO}_{4}^{2 \cdot}$ entre os tratamentos, sendo inferior a $10 \mathrm{mg} \mathrm{dm}^{-3}$. Comumente, o teor de enxofre (S) não excede 10 a $15 \mathrm{mg} \mathrm{dm}^{-3}$, sendo freqüentemente menor do que 5 a $10 \mathrm{mg} \mathrm{dm}^{-3}$ em solos de Cerrado (Rocha e Malavolta, 1988). Na camada de 20 a $40 \mathrm{~cm}$ (Figura 2a) houve aumento similar no teor de $\mathrm{S}_{-} \mathrm{SO}_{4}^{2-}$ acima de 20,0 $\mathrm{mg} \mathrm{dm}^{-3}$, nos tratamentos com aplicação de sulfato de amônio e uréia + sulfato de amônio, indicativo de suplementação de $\mathrm{S}$ pelas fontes de fertilizantes.

\begin{tabular}{|llll}
\hline $\mathrm{SA}+\mathrm{U}$ & $\mathrm{SA} \quad \mathrm{U} \cup$ Testemunha \\
\hline
\end{tabular}

Concentração de S-SO ${ }_{4}^{2-}, \mathrm{mg} \mathrm{dm}^{-3}$

a)

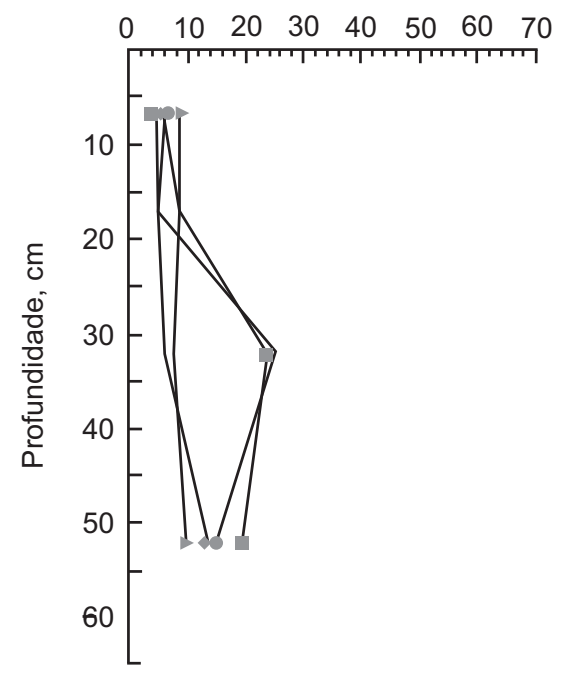

b)

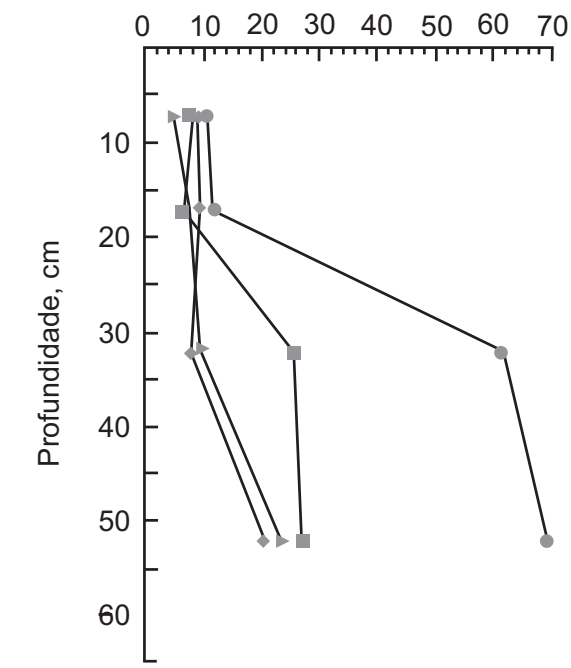

Figura 2. Distribuição de $\mathrm{S}^{-\mathrm{SO}_{4}}{ }^{2-}$ no perfil de solo na entrelinha: a) sete dias após a aplicação da segunda cobertura nitrogenada (10 a 12 folhas) e b) 23 dias após o pendoamento do milho, das fontes uréia (U), sulfato de amônio (AS e mistura U + AS (1:1 de N), independentemente da presença de Brachiaria ruziziensis. Uberlândia (MG), dezembro de 2003.
Com a aplicação exclusiva de uréia ao longo das camadas em profundidade não houve aumento no teor de $S$ em relação à testemunha. Todavia, aumento significativo no teor de $\mathrm{S}^{-} \mathrm{SO}_{4}^{2-}$ foi observado nas camadas de 20 até $60 \mathrm{~cm}$, entre 60 a $70 \mathrm{mg} \mathrm{dm}^{-3}$, aos 23 dias após a segunda cobertura nitrogenada, no tratamento exclusivo de sulfato de amônio (Figura 2b). Segundo Bissani e TeDesco (1988), o padrão de distribuição de S no perfil é influenciado pelo manejo do solo. No caso de solos cultivados, como foi o objeto deste estudo, ocorreu um aumento expressivo no teor de $S$ na camada imediatamente inferior àquela cultivada, indicativo de lixiviação da camada superficial do solo devida à adubação. Em função do acúmulo da precipitação pluvial até essa época e da aplicação em ambas as coberturas, deve ter havido influência na disponibilidade de grande proporção do $\mathrm{S}$ aplicado via sulfato de amônio $\left(119,6 \mathrm{~kg} \mathrm{ha}^{-1}\right)$ e no seu aproveitamento pelas raízes do milho, com reflexo na produtividade de grãos. Nos demais tratamentos, constatou-se distribuição similar nos teores de $\mathrm{SO}_{4}^{2-}$ aos registrados na primeira época, apesar de poder ser favorecida a oxidação de S-orgânico, pelas condições ambientais - aeração, temperatura, umidade e $\mathrm{pH}$ da solução do solo, como indicado por Stevenson e Cole (1999). Na tabela 1, são mostrados os teores de $\mathrm{N}$ e $\mathrm{S}$ avaliados nos dois sistemas de manejo, a altura de plantas e o diâmetro de colmos, avaliados por ocasião do florescimento do milho, unicamente nos tratamentos de milho solteiro. Verificou-se que os maiores teores numéricos de $\mathrm{N}$ foliar foram obtidos com as fontes de $\mathrm{S}$ e, com maior teor foliar de $\mathrm{S}$ porém, sem diferenças estatísticas. Os teores estavam adequados para $S$ e no limite inferior de suficiência para $N$, segundo Büll e Cantarella (1993). Dentre os tratamentos de adubos nitrogenados não foram observadas diferenças significativas na altura de plantas nem no diâmetro de colmos.

Nas tabelas 2 e 3 têm-se os efeitos das fontes de cobertura nitrogenada, aplicadas nos estádios de dois a três folhas e cinco a seis folhas, respectivamente, no acúmulo de MMS e de $\mathrm{N}$, além da eficiência de seu aproveitamento. No estádio de duas a três folhas não houve diferença significativa para o $\mathrm{N}_{p p f}$ e para a eficiência dos fertilizantes aplicados, na presença e ausência de braquiária. Valor médio de $18,0 \mathrm{~kg} \mathrm{ha}^{-1}$ de $\mathrm{N}_{p p f}$ e, portanto, de $45 \%$ de eficiência, foi obtido para o milho nos dois sistemas de manejo, quando aplicados $40 \mathrm{~kg} \mathrm{ha}^{-1} \mathrm{de} \mathrm{N}$. Do Ntotal assimilado pela cultura (solo+fertilizante), médias de $183,6 \mathrm{~kg} \mathrm{ha}^{-1}$ e $190,7 \mathrm{~kg} \mathrm{ha}^{-1}$ no milho consorciado e solteiro, respectivamente, $9,8 \%$ e $9,4 \%$ foram as contribuições do N-fertilizante aplicado em cobertura, independentemente das fontes utilizadas. 
Tabela 1. Teores foliares de $\mathrm{N}$ e $\mathrm{S}$ na planta de milho, em cultivo solteiro e consorciado à Brachiaria ruziziensis e altura de plantas e diâmetro de colmos de milho, após adubação nitrogenada em cobertura, em sistema plantio direto. Uberlândia (MG), 2002/2003

\begin{tabular}{|c|c|c|c|c|c|c|c|c|}
\hline \multirow{2}{*}{ Fontes de nitrogênio } & \multicolumn{2}{|c|}{$\mathrm{N}$ - foliar } & \multirow{2}{*}{ Média } & \multicolumn{2}{|c|}{$S$ - foliar } & \multirow{2}{*}{ Média } & \multirow{2}{*}{$\begin{array}{c}\text { Altura } \\
\text { das plantas }\end{array}$} & \multirow{2}{*}{$\begin{array}{l}\text { Diâmetro } \\
\text { de colmos }\end{array}$} \\
\hline & Consórcio & Solteiro & & Consórcio & Solteiro & & & \\
\hline & & +2 & $\mathrm{~g} \mathrm{~kg}^{-1}$ & & 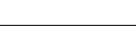 & & $\mathrm{m}$ & $\mathrm{cm}$ \\
\hline Testemunha & $23,2 \mathrm{Aa}$ & $25,2 \mathrm{Aa}$ & 24,2 & $2,1 \mathrm{Ba}$ & $2,1 \mathrm{Aa}$ & 2,1 & $1,96 \mathrm{~A}$ & $1,43 \mathrm{~A}$ \\
\hline $\begin{array}{l}\text { Sulfato de amônio } \\
\text { Uréia }\end{array}$ & $\begin{array}{l}27,1 \mathrm{Aa} \\
24,8 \mathrm{Aa}\end{array}$ & $\begin{array}{l}27,8 \mathrm{Aa} \\
27,0 \mathrm{Aa}\end{array}$ & $\begin{array}{l}27,5 \\
25,9\end{array}$ & $\begin{array}{l}2,6 \mathrm{Aa} \\
2,2 \mathrm{ABa}\end{array}$ & $\begin{array}{l}2,7 \mathrm{Aa} \\
2,7 \mathrm{Aa}\end{array}$ & $\begin{array}{l}2,7 \\
2,5\end{array}$ & $\begin{array}{ll}1,96 & \mathrm{~A} \\
1,96 & \mathrm{~A}\end{array}$ & $\begin{array}{l}1,47 \mathrm{~A} \\
1,48 \mathrm{~A}\end{array}$ \\
\hline Sulfato de amônio + uréia & $26,8 \mathrm{Aa}$ & $28,7 \mathrm{Aa}$ & 27,8 & $2,4 \mathrm{ABa}$ & $2,3 \mathrm{Aa}$ & 2,3 & $1,98 \mathrm{~A}$ & $1,47 \mathrm{~A}$ \\
\hline Média & 25,5 & 27,2 & & 2,3 & 2,5 & & & \\
\hline D.M.S. (entre manejos) & 5,20 & & & 0,80 & & & 0,75 & \\
\hline D.M.S. (entre fontes) & 3,12 & & & 0,71 & & & 0,63 & \\
\hline C.V. $(\%)$ & 12,9 & & & 3,3 & & & 1,3 & \\
\hline
\end{tabular}

Médias seguidas por letras distintas, minúsculas na linha e maiúsculas na coluna, são diferentes entre si pelo teste de Tukey em nível de $5 \%$ de significância.

$\mathrm{Na}$ tabela 3, constam os valores de $\mathrm{N}_{p p f}$ e as eficiências dos fertilizantes nitrogenados aplicados no estádio de cinco a seis folhas, na presença e ausência de braquiária em consórcio. Em média, na presença de braquiária e, independentemente das fontes nitrogenadas, a eficiência de recuperação foi de $60,7 \%$ do $\mathrm{N}$ aplicado, correspondendo a $38,9 \mathrm{~kg} \mathrm{ha}^{-1}$ dos 64 $\mathrm{kg} \mathrm{ha}^{-1}$ de $\mathrm{N}$ aplicados, sendo aumentada significativamente a eficiência em relação à primeira cobertura. As maiores eficiências de recuperação do $\mathrm{N}$ aplicado foram, em ordem decrescente, do N-sulfato de amônio, N-uréia + sulfato de amônio e N-uréia $75,1 \%, 57,9 \%$ e $49,1 \%$ respectivamente, não havendo diferença significativa entre os tratamentos. $\mathrm{Na}$ ausência de braquiária, observou-se que a eficiência média dos fertilizantes nitrogenados foi de $51,6 \%$ do $\mathrm{N}$ aplicado, sendo inferior, em média, 9,1\% em relação à quantificada na presença da braquiária, o que poderia parecer contrário ao esperado. Com o cultivo do milho em consórcio não foi afetada negativamente a assimilação de $\mathrm{N}$-fertilizante, e sim atuação de forma sinérgica, o que é merecedor de estudos na rizosfera para maior compreensão desse processo. Pelos resultados deste manejo, verifica-se que a fonte sulfato de amônio foi mais eficiente, sendo 75,1\% maior em relação às outras fontes utilizadas.

Em geral, a cobertura foi mais eficiente no estádio de cinco a seis folhas, quando o sistema radicular está mais bem desenvolvido, possibilitandose mais assimilação de $\mathrm{N}$ e $\mathrm{S}$. Cabe salientar que, nesse estádio, a seqüência decrescente de eficiência está relacionada à menor concentração de $\mathrm{S}$ no fertilizante, tanto na presença como na ausência de braquiária, sendo: sulfato de amônio > uréia + sulfato de amônio > uréia. De fato, a análise foliar é reflexo dessa situação (Tabela 1).
O $\mathrm{N}_{p p f}$ recuperado pela braquiária, somando-se os dois parcelamentos, foi de $1,6 \mathrm{~kg}$ ha-1 - 1,5\% de eficiência de recuperação, independentemente das fontes aplicadas (Tabela 4). Por sua vez, o $\mathrm{N}_{p p f}$, nos dois parcelamentos para o milho, independentemente das fontes aplicadas, foi de $52,9 \mathrm{~kg} \mathrm{ha}^{-1}$ de $\mathrm{N}-50,8 \%$ de eficiência em média de recuperação. Tendo como base 100 o Ntotal fertilizante assimilado em ambas as culturas - 54,5 kg ha ${ }^{-1}$ de $\mathrm{N}\left(52,9 \mathrm{~kg} \mathrm{ha}^{-1}+1,6 \mathrm{~kg}\right.$ ha- 1$)$, $97,1 \%$ e $2,9 \%$ do $\mathrm{N}_{p p f}$ ficaram distribuídos entre o milho e a braquiária, respectivamente, indicativo direto de ausência de competição entre a forrageira e a cultura do milho pela assimilação do N.

Diversos autores relatam que as produtividades de grãos e de silagem de milho solteiro em relação às do consórcio com diversas forrageiras, não são diferentes (AGNES et al., 2004; CAPOBIANCO et al., 2004; Mateus et al., 2004; Tsumanuna et al., 2004). Tampouco, em termos bromatológicos, a qualidade da forragem de milho foi negativamente afetada pelo consórcio com B. brizantha (BORGHI et al., 2004).

Para a produção de MMS de braquiária até a colheita de milho obteve-se um valor médio de 305,5 $\mathrm{kg} \mathrm{ha}^{-1}$ na parte aérea, independentemente das fontes nitrogenadas utilizadas e dos parcelamentos (Tabela 4). Com esse resultado, verifica-se que a braquiária foi efetiva e negativamente afetada pelo milho, com um inexpressivo consumo de N-fertilizante. Para cada parcelamento, não se observou diferença em produção de MMS, N-total acumulado e em Nppf entre as fontes utilizadas. PORTes et al. (2000) verificaram que a $B$. brizantha foi prejudicada em seu desenvolvimento pelo sombreamento do milho, sendo aquela de metabolismo $\mathrm{C}_{4}$ de fixação de $\mathrm{CO}_{2}$. 


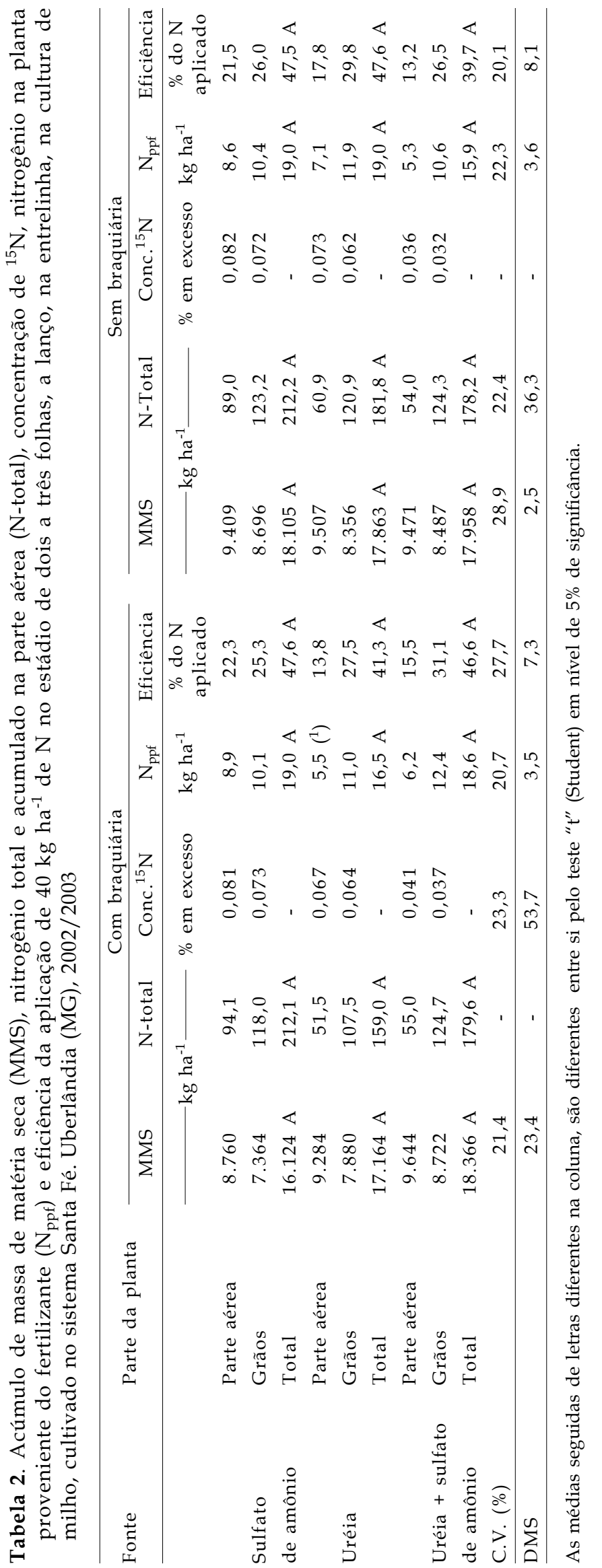

ฮั

สี ำำ

ฮ

음

奈 Z

छ

ชิ

준

웅ㅇㅇ

-융 ते

is

藏.

के

$\sum \pi$

氙

준

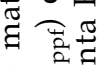

ชี ڤึ

ฮ

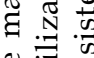

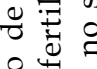

눙웜

ن

ก

范

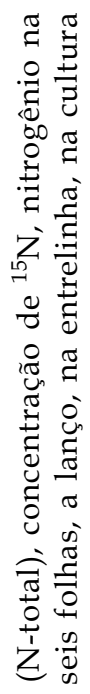

푤

용

党:

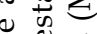

สี

ส

웜

สำ.

है

ब $\forall \cdot \frac{N}{N}$

ช

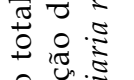

灵苟

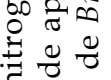

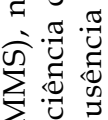

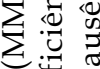

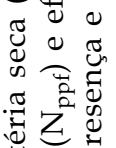

๘

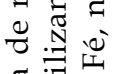

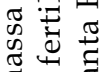

๕ี

ช ญ

월.

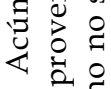

के

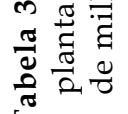

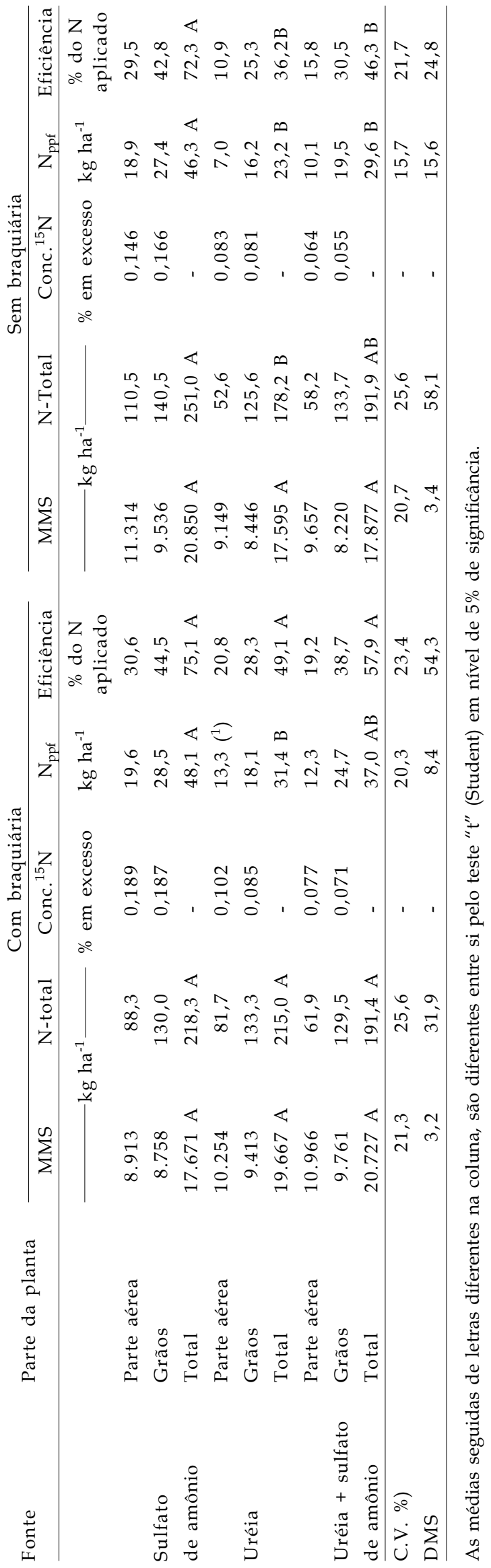


Tabela 4. Acúmulo de massa de matéria seca de Brachiaria ruziziensis (MMS), nitrogênio total acumulado (N-total), concentração de ${ }^{15} \mathrm{~N}, \mathrm{~N}$ na planta proveniente do fertilizante $\left(\mathrm{N}_{\mathrm{ppf}}\right)$ e a eficiência de $\mathrm{N}$ aplicado em cobertura parcelada, nas entrelinhas do milho, no sistema Santa Fé. Uberlândia, (MG), 2002/200.

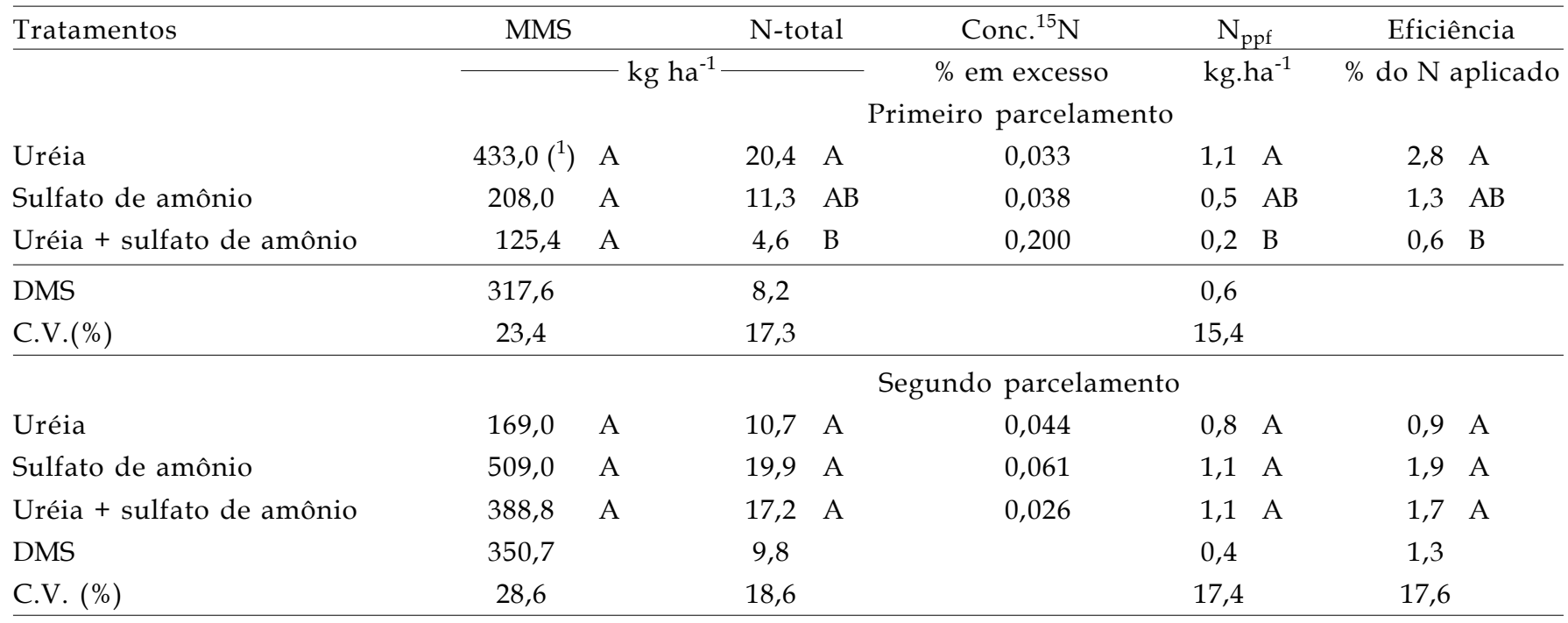

(1) Médias seguidas por letras distintas, minúsculas na linha e maiúsculas na coluna, são diferentes entre si pelo teste de Tukey em nível de $5 \%$ de significância.

Tabela 5. Acúmulo de massa de matéria seca de milho (MMS) e produtividade de grãos em função de diferentes fontes de nitrogênio aplicadas em cobertura, na cultura de milho cultivado no sistema Santa Fé. Uberlândia (MG), 2002/2003

\begin{tabular}{|c|c|c|c|c|c|c|c|}
\hline \multirow{3}{*}{ Tratamentos } & \multicolumn{4}{|c|}{ Massa de matéria seca } & \multicolumn{3}{|c|}{ Produtividade } \\
\hline & \multicolumn{2}{|c|}{ Consórcio } & \multicolumn{2}{|c|}{ Solteiro } & \multicolumn{2}{|c|}{ Consórcio } & \multirow[t]{2}{*}{ Solteiro } \\
\hline & \multicolumn{4}{|c|}{$\mathrm{kg} \mathrm{ha}^{-1}$} & \multicolumn{2}{|c|}{$\mathrm{kg} \mathrm{ha}^{-1}$} & \\
\hline Testemunha & 6.635 & $\mathrm{Ba}$ & 6.811 & $\mathrm{Ba}$ & 7.502 & $\mathrm{aB}$ & $6.803 \mathrm{aB}$ \\
\hline Sulfato de amônio & 8.838 & $\mathrm{ABb}$ & 10.171 & $\mathrm{Aa}$ & 8.780 & $\mathrm{aA}$ & $8.214 \mathrm{aAB}$ \\
\hline Uréia & 9.406 & $\mathrm{ABa}$ & 9.292 & $\mathrm{Aa}$ & 8.634 & $\mathrm{aAB}$ & 7.998 aAB \\
\hline Uréia + sulfato de amônio & 9.844 & Aa & 9.564 & Aa & 7.989 & $\mathrm{aAB}$ & 8.450 aA \\
\hline DMS (fontes) & & 1.605 & & & & 1.650 & \\
\hline DMS (sistemas manejo) & & 1.028 & & & & 656 & \\
\hline C.V.(\%) & & 13,3 & & & & 12,3 & \\
\hline
\end{tabular}

Médias seguidas por letras distintas, minúsculas na linha e maiúsculas na coluna, diferem entre si pelo teste de Tukey em nível de 5\% de significância.

Após 55 dias da colheita de milho, houve um acréscimo significativo da MMS de braquiária, sendo, na média dos tratamentos, de $916,8 \mathrm{~kg} \mathrm{ha}^{-1}$, representativo de taxa média de acúmulo de 16,7 $\mathrm{kg} \mathrm{ha}{ }^{-1} \cdot \mathrm{dia}^{-1}$. PORTes et al. (2000) registraram tendência semelhante, possibilitando a utilização da forrageira aos 70 dias após a colheita dos cereais. No caso desses autores, foi efetuada a semeadura simultânea da braquiária e do cereal, fato que parece mais conveniente, em relação à semeadura defasada, caso deste estudo, a fim de favorecer um crescimento mais expressivo antes do período de maior sombreamento pelo milho.
Na tabela 5 estão os dados da produção de MMS e da produtividade de milho entre as fontes utilizadas e do manejo, milho solteiro e em consórcio.

A produção de MMS, para cada sistema de manejo, não foi negativamente afetada pelas fontes nitrogenadas utilizadas na cobertura. Esse fato somente ocorreu em relação à testemunha. Entre os sistemas de manejo, somente com o sulfato de amônio propiciou maior produção de MMS $\left(10,2 \mathrm{t} \mathrm{ha}^{-1}\right)$ para o milho solteiro em relação ao consorciado $\left(8,9 \mathrm{t} \mathrm{ha}^{-1}\right)$, evidenciando a importância da aplicação do enxofre na cobertura nitrogenada. Nos sistemas consórcio e 
do milho solteiro não houve diferença de produtividade entre as fontes de $\mathrm{N}$, ocorrendo apenas em relação à testemunha. Tampouco foi observada diferença para cada fonte aplicada, entre os sistemas de manejo. A média de produtividade nos tratamentos com adubação nitrogenada, independentemente da fonte e do manejo, foi de $8.344 \mathrm{~kg} \mathrm{ha}^{-1}$ em relação à da testemunha, que foi de $7.153 \mathrm{~kg} \mathrm{ha}^{-1}$, representando um acréscimo de 16,7\%, devido à adubação nitrogenada em cobertura.

\section{CONCLUSÕES}

1. Na cultura de milho, há mais acúmulo do $\mathrm{N}$-fertilizante em relação à da Brachiaria ruziziensis.

2. A eficiência média das fontes nitrogenadas em milho solteiro e consorciado é maior quando aplicadas no estádio de cinco a seis folhas.

3. Na cultura do milho solteiro há mais concentração de $\mathrm{SO}_{4}^{2-}$ nas camadas de $20 \mathrm{~cm}$ até 60 cm de profundidade, aos 23 dias após uma segunda cobertura nitrogenada.

\section{AGRADECIMENTOS}

Os autores deste estudo agradecem os recursos financeiros outorgados pela empresa Honeywell-SN-Centro de Pesquisa e Promoção de Sulfato de Amônio (SN-Centro) e à Fundação AGRISUS/Fealq. Tornam-se extensivos os agradecimentos aos discentes que participaram de forma voluntária na coleta de dados.

\section{REFERÊNCIAS}

AGNES, E. L.; FREITAS, F.C.L.; FERREIRA, L.R. Situação atual da Integração Agricultura-Pecuária em Minas Gerais e na Zona da Mata Mineira. In: ZAMBOLIM, L.; SILVA, A.A.; AGNES, E.L. (Ed.). Manejo da Integração Agricultura-Pecuária. Viçosa,: Universidade Federal de Viçosa, 2004. p. 251-268.

ANGHINONI, I.; SALET, L.R. Amostragem do solo e as recomendações de adubação e calagem no sistema plantio direto. In: NUERNBERG, N.J. (Ed.). Conceitos e fundamentos do sistema plantio direto. Lages: Sociedade Brasileira de Ciência de Solo - Núcleo Regional Sul, 1998. p. 27-52.

BISSANI, C.A.; TEDESCO, M.J. O enxofre no solo. In: BORKERT, C.M.; LANTMANN, A.F.(Ed.). Enxofre e micronutrientes na agricultura brasileira. Londrina: Embrapa/IAPAR/SBCS, 1988. p. 11-29.
BORGES, E.P. História do processo Integração AgriculturaPecuária. In: ZAMBOLIM, L.; SILVA, A.A.; AGNES, E.L. (Ed.). Manejo da Integração Agricultura-Pecuária. Viçosa, MG: Universidade Federal de Viçosa, 2004. p. 353-384.

BORGHI, E.; CRUSCIOL, C.A.; MATEUS, G.P.; COSTA, C. Composição químico-bromatológica da forragem de milho em consórcio com $B$. brizantha em sistema plantio direto. In: CONGRESSO NACIONAL DE MILHO E SORGO, 25., 2004, Cuiabá, MT. Resumos...Cuiabá: ABMS, 2004. (1 CD-ROM)

BÜLL, L.T.; CANTARELLA, H. Cultura do milho: fatores que afetam a produtividade. 2.ed. Piracicaba: POTAFOS, 1993.301p.

CAMPOS, A.X.. Fertilização com sulfato de amônio em présemeadura e cobertura na cultura de milho em um solo do cerrado de Brasília sob pastagem de B. decumbens. 2004. 119f. Tese (Doutorado) - Centro de Energia Nuclear na AgriculturaCENA/USP, Piracicaba, 2004.

CANTARELLA, H.; PROSCHNOW, L.I. Determinação de sulfatos em solos. In: RAIJ, B.; ANDRADE, J.C.; CANTARELLA, H.; QUAGGIO, J.A. (Ed.). Análise Química para Avaliação da Fertilidade de Solos Tropicais. Campinas: Instituto Agronômico, 2001. p. 225-230.

CAPOBIANCO, R.; MELLO, K.V.V.S.; MATEUS, G.P.; CRUSCIOL, C.A.C.; BORGHI, E. Produção do milho em consórcio com a B. brizantha em função da adubação nitrogenada: II. Produtividade de grãos. In: REUNIÃO BRASILEIRA DO SOLO E NUTRIÇÃO DE PLANTAS, 26., 2004, Lages, SC. Resumos... Lages: FERTBIO-SBCS, 2004. (1 CD-ROM)

EMPRESA BRASILEIRA DE PESQUISA AGROPECUÁRIA EMBRAPA. Sistema brasileiro de Classificação de Solos. Brasília: Embrapa Produção de Informação; Rio de Janeiro: Embrapa Solos, 1999. 412p.

FANCELLI, A.L.; DOURADO NETO, D. Produção de milho. Guaíba: Agropecuária, 2000.360p.

KLUTHCOUSKI, J.; AIDAR, H. Implantação, condução e resultados obtidos com o sistema Santa Fé. In: KLUTHCOUSKI, J.; STONE, L.F.; AIDAR, H. (Ed.). Integração lavoura - pecuária. Santo Antônio de Goiás: Embrapa Arroz e Feijão, 2003. p. 407-441.

KLUTHCOUSKI, J.; AIDAR, H.; STONE, L.F.; COBUCCI, T. Integração lavoura-pecuária e o manejo de plantas daninhas. In: SIMPÓSIO SOBRE SISTEMA AGRÍCOLA SUSTENTÁVEL COM COLHEITA ECONÔMICA MÁXIMA, 1, 2004, Piracicaba, SP. Resumos... Piracicaba: POTAFOS, 2004. (1 CD-ROM)

MALAVOLTA, E.; VITTI, G.C.; OLIVEIRA, S.A. Avaliação do estado nutricional das plantas: pricípios e aplicações, 2.ed. Piracicaba: POTAFOS, 1997.319p.

MATEUS, G.P.; BORGHI, E.; CRUSCIOLI, C.; COSTA, C. Produção de forragem de milho com $B$. brizantha em sistema plantio direto. In: CONGRESSO NACIONAL DE MILHO E SORGO, 25., 2004, Cuiabá. Resumos...Cuiába: ABMS, 2004. (1 CD-ROM) 
OLIVEIRA, P.P.A. Manejo da calagem e da fertilização nitrogenada na recuperação de pastagens degradadas de Brachiaria spp. 2001. 107 p. Tese (Doutorado) - Centro de Energia Nuclear na Agricultura, CENA/USP, Piracicaba, 2001.

PORTES, T.A.; CARVALHO, S.I.C.; OLIVEIRA, I.F.; KLUTHCOUSKI, J. Análise do crescimento de uma cultivar de braquiária em cultivo solteiro e consorciado com cereais. Pesquisa Agropecuária Brasileira, Brasília, v. 35, p. 1.349-1.358, 2000.

RAMOS, M.G; VILLATORO, M.A.A.; URQUIAGA, S.; ALVES, B.J.R.; BODDEY, R.M. Quantification of the contribution of biological nitrogen fixation to tropical green manure crops and the residual benefit to a subsequent maize crop using ${ }^{15} \mathrm{~N}$ isotope techniques. Journal of Biotechnology, London, v. 91, n. 2/3, p. 105-115, 2001.

ROCHA, M.; MALAVOLTA, E. Perspectivas de demanda, comercialização e produção industrial de enxofre e micronutrientes para a agricultura. In: BORKERT, C.M.; LANTMANN, A.F. (Ed.). Enxofre e micronutrientes na agricultura brasileira. Londrina: Embrapa/IAPAR/SBCS, 1988. p. 277-308.
SALTON, J.C.; HERNANI, L.C.; BORGES, E.P. Avaliação do sistema plantio direto na sucessão de soja sobre pastagens de braquiária. In: CONGRESSO BRASILEIRO DE CIÊNCIA DO SOLO, 1995. Viçosa. Anais... Viçosa: SBCS/UFV, 1995. v.4, p. 1816-1818.

STEVENSON, F.J.; COLE, M.A. Cycles of soil: carbon, nitrogen, phosphorus, sulfur, micronutrients, 2.ed. Urbana-Champaign: John Willey \& Sons, 1999. 427p.

TSUMANUMA, G.M.; FANCELLI, L.A.; BALDO, M.N.; MARCONDES, L.P. Comportamento do milho consorciado com diferentes espécies de braquiárias. In: CONGRESSO NACIONAL DE MILHO E SORGO, 25., 2004, Cuiabá. Resumos... Cuiába: ABMS, 2004. (1 CD-ROM) 